\title{
研究
}

\section{A compact optical fiber hydrophone using fiber Bragg grating}

\author{
高橋 信明，吉村和人，高橋 純夫* \\ (防衛大学校) \\ 今村一雄** \\ (三菱電線工業 (株) \\ (平成11年7月13日受付け)
}

\begin{abstract}
A compact optical fiber hydrophone with a fiber Bragg grating (FBG) is developed and experimentally examined. The developed FBG hydrophone exhibits linear response to a sound pressure in water with the dynamic range as wide as $90 \mathrm{~dB}$. It can detect an acoustic field in the wide range of frequency: it operates at least from a few tens $\mathrm{kHz}$ to a few $\mathrm{MHz}$. It can also measure an acoustic field with fairly good spatial resolution. Because of the simplicity in the geometry and potentially low cost in the production, an FBG is expected to offer a practically important hydrophone of high performance.
\end{abstract}

\section{Abstractの日本語訳}

ファイバブラッググレーティング(FBG)を用いたコンパクトな光ファイバハイドロホンが試作され, 実験的に吟味されている。FBGハイドロホンは $90 \mathrm{~dB}$ に及ぶダイナミックレンジを持ち，水中の音圧 に対し線形に応答する。それは広範囲の周波数の音場を検出することができる。少なくとも数十 $\mathrm{kHz}$ ら数 MHzの範囲に亘って動作する。また，かなり良い空間分解能で音場を測定することも可能である。 機構の簡単さ及び潜在的な製造コストの低さのため, FBG は実用上重要な高性能ハイドロホンを提供 すると期待される。

\section{Introduction}

An optical fiber Bragg grating (FBG) has been widely utilized as a sensing tool for various physical quantities including acoustic field, temperature and strain. ${ }^{1-5)}$ Specifically underwater acoustic sensing has successfully been demonstrated using an FBG in combination with a laser light ${ }^{1)}$

* Nobuaki TAKAHASHI, Kazuto YOSHIMURA, Sumio TAKAHASHI(National Defense Academy)

** Kazuo IMAMURA( Mitsubishi Cable Industries, Ltd.) instead of a broad-spectrum light source that most researchers use for FBG sensors. ${ }^{3)}$ In comparison with an optical fiber hydrophone of conventional type, $\left.{ }^{6}\right)$ an FBG underwater acoustic sensor carries important features from the view point of practical applications. While the operation principle of a conventional fiber hydrophone is based on a phase shift of a light propagating in a fiber induced by an external sound pressure, that of an FBG acoustic sensor is based on direct intensity modulation of a light trans- 
mitting through or reflecting back from an FBG under influence of a sound pressure. Measurement of optical intensity is generally easier than that of optical phase. In addition, phase shift of a laser light propagating in a leading fiber which is caused by a mechanical disturbance from environment is considered to have little influence on the performance of an FBG acoustic sensor unlike in the case of a conventional fiber hydrophone. The length of an FBG for acoustic sensing can be made short, e.g., as short as a few millimeters, compared with that of a sensing fiber in a conventional fiber hydrophone, in which the sensing fiber is usually wound into circles in order to enhance the sensitivity of the sensor. An FBG is therefore expected to provide an inexpensive optical fiber hydrophone in a simple geometry. In this paper we show a prototype of a compact optical fiber hydrophone using an FBG and examine its performance. After measuring the fundamental characteristics, a spatial distribution of an acoustic field in water is measured as an application of the sensor developed.

\section{Background}

An FBG shows a characteristic reflection in the neighborhood of the Bragg reflection wavelength of an FBG given by

$$
\lambda_{B}=2 n_{0} \Lambda
$$

where $n_{0}$ is the effective index of refraction of the FBG fiber core and $\Lambda$ is the pitch of the grating in the FBG. ${ }^{7)}$ That is, the reflectance of the an FBG, $R(\lambda)$, is largest when the wavelength of an incident light is equal to $\lambda_{B}$ and decreases rapidly as the wavelength departs from $\lambda_{B}$ in either shorter or longer wavelength side. When a sound pressure $p$ is applied to an FBG, the reflectance spectrum curve moves in synchronization with the sound pressure. The intensity of the reflected light is then given by

$$
\begin{aligned}
I_{r} & =I_{\text {in }} R\left(\lambda_{\text {in }}\right) \\
& =\left.I_{\text {in }} R\left(\lambda_{\text {in }}\right)\right|_{p=0}+I_{\text {in }} \frac{d R\left(\lambda_{\text {in }}\right)}{d p} p
\end{aligned}
$$

where $I_{\text {in }}$ and $\lambda_{\text {in }}$ are the intensity and wavelength of an incident light, respectively. In deriving the above equation, we have assumed that the change in the reflection spectrum curve induced by a sound pressure around the FBG is small and accordingly the higher order terms can be neglected, which is indeed the case for the sound pressure of our interest. ${ }^{7)}$ Since it is known from the discussion in Ref. 7 that the reflection spectrum curve moves without changing its shape as a pressure is applied, the above equation may be rewritten as

$$
I_{r}=\left.I_{\mathrm{in}} R\left(\lambda_{\mathrm{in}}\right)\right|_{p=0}+I_{\mathrm{in}} \frac{\partial R\left(\lambda_{\mathrm{in}}\right)}{\partial \lambda} \xi p
$$

where $\xi$ is the rate of shift in the Bragg reflection wavelength as a pressure is applied to the FBG. It is seen therefore from Eq. (3) that the $\mathrm{AC}$ component (second term) of the reflected light intensity is proportional to the sound pressure. The steeper the slope of the reflection spectrum curve is, the larger the signal can be obtained.

\section{Experiments and discussions}

\subsection{Compact hydrophone with FBG}

When an FBG is utilized as an acoustic sensor based on the direct intensity modulation of a laser light in the FBG under influence of a sound pressure, one can obtain the sensor signal from the light either transmitted through or reflected back from the FBG. Since the reflection mode of the operation offers higher compactness in the sensor geometry than the transmission mode, we have constructed an FBG hydrophone in the reflection mode. Fig.1 shows a head of a prototype of an optical fiber hydrophone that uses an FBG as a sensing element. Specifications of the FBG used for the sensor are as follows. The 


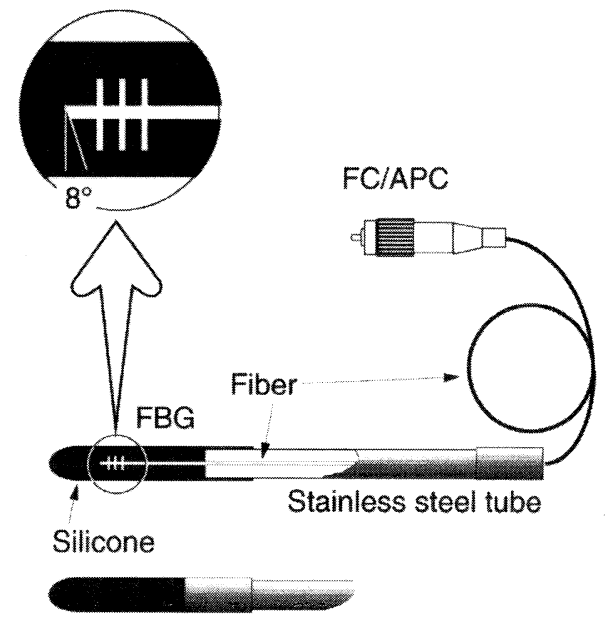

Fig.1 FBG hydrophone.

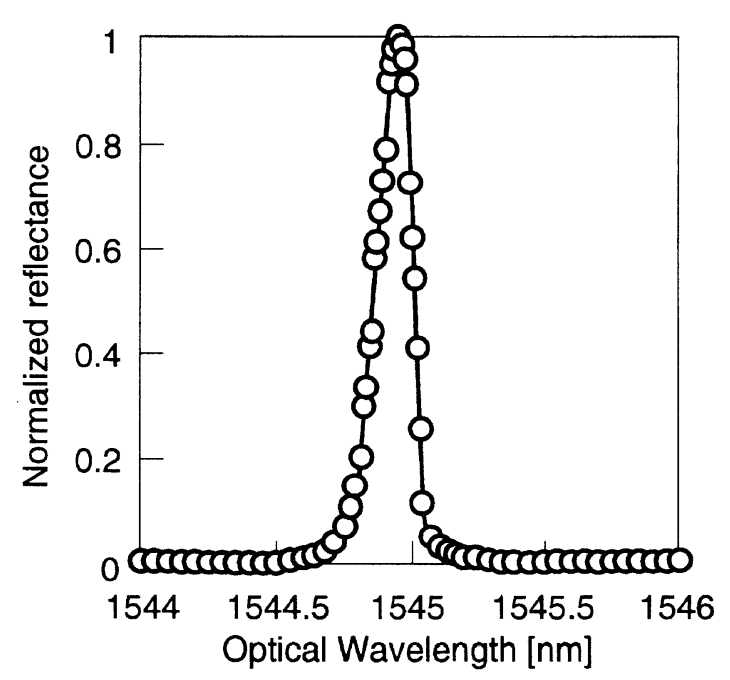

Fig.2 Reflection spectrum of FBG.
Bragg reflection wavelength is $1544.7 \mathrm{~nm}$. The wavelength bandwidth of the reflection is 0.14 $\mathrm{nn}$. The reflectance at the Bragg reflection wavelength is 99 percent. The length of the FBG is 24 $\mathrm{mm}$. Fig.2 shows the reflection spectrum of the FBG, which was measured by using ASE (Amplified Spontaneous Emission) output from an EDFA (Erbium-Doped Fiber Amplifier) as an optical source and an optical spectrum analyzer as a detecting system. Since the measurement includes various losses due to the optical connections and fusion splicing, the reflectance on the vertical axis is normalized to unity and given in relative magnitude. The $F B G$ is embedded in silicone that is supported by a stainless steel tube. The dimensions of the FBG hydrophone head are $210 \mathrm{~mm}$ in length and $8 \mathrm{~mm}$ in diameter. For the stabilization of the sensor operation, one end of the FBG fiber is cut at the angle of 8 degrees and an FC/APC (angled PC) optical fiber connector is connected to the other end of the fiber. When there is reflection from various facets and/or optical connectors of low quality, there may be Fabry-Perot interference between the FBG, facets and connectors, which results in fluctuation of the sensor operation. In the development of the FBG

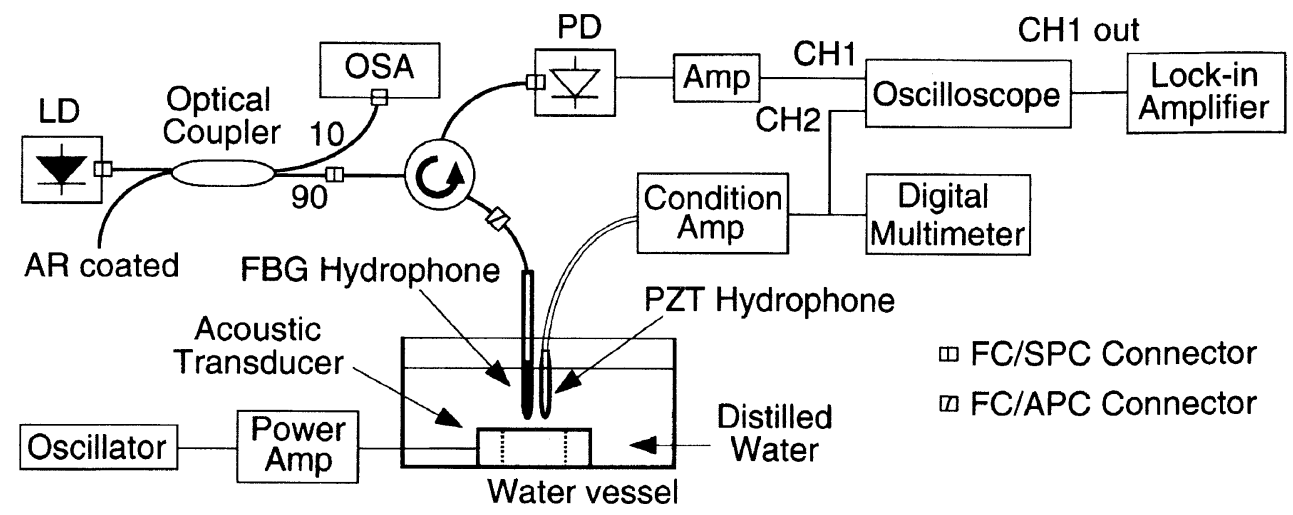

Fig.3 Experimental setup for FBG hydrophone. In the connections, thin line is an electric wire and thick line is an optical fiber. 
underwater acoustic sensor in the transmission mode, optical isolators are inserted before and after the FBG in order to keep out the FabryPerot interference. ${ }^{1)}$ For the operation of the sensor in the reflection mode, however, an optical isolator can not be used and therefore the reflection from various facets and/or discontinuities need to be suppressed as much as possible for the operation of high stability. The cut angle was examined by measuring a frequency histogram of the sensor output signal while varying the angle and has been determined to be 8 degrees. We also examined two kinds of optical connectors FC/SPC (super PC) and FC/APC, which have nominally the back reflection of about -40 and $-60 \mathrm{~dB}$, respectively. An FC/APC connector has the least back reflection among commercially available optical fiber connectors at the moment. When we used an FC/SPC connector in the sensor, we observed the slow (less than $1 \mathrm{~Hz}$ ) temporal fluctuation of the detected signal. When we used an FC/APC connector instead, the sensor output is stabilized and we did not see the temporal fluctuation at least during the observation in the laboratory, i.e., more than a few tens minutes. For the operation of the sensor, this sensor head is connected to an optical circulator through which a laser light is supplied and the sensor signal is extracted.

\subsection{Fundamental characteristics}

Using the experimental setup shown in Fig. 3, an acoustic field in water is measured with the FBG hydrophone developed. The FBG hydrophone head is placed in a water vessel filled with distilled water. On the bottom of the vessel there is a PZT acoustic transducer driven by an oscillator and a power amplifier. LD is a wavelength-variable laser diode and its output wavelength is tuned to the slope of the reflection spectrum curve of the FBG: the operating wavelength is thus chosen to be $1544.67 \mathrm{~nm}$. The output power of the laser diode is $3 \mathrm{~mW}$. An optical coupler and an optical spectrum analyzer are inserted to monitor the incident light on the FBG. As mentioned in the previous section, an optical circulator is used to efficiently introduce the light from the source to the FBG and again from the FBG to the photo detector. The reflected light from the FBG is detected with a photodiode PD, amplified by an amplifier and observed on an oscilloscope (CH1). For comparing the performance, a PZT hydrophone is placed near the FBG hydrophone. The output of the PZT hydrophone is also observed on the oscilloscope (CH2). Fig.4 (a) shows the observed oscillograms of the FBG hydrophone and PZT hydrophone for an acoustic frequency at $20 \mathrm{kHz}$ in continuous mode. Fig.4 (b) and (c) show those at 1 and $3 \mathrm{MHz}$ in pulsed mode. The upper traces in all figures correspond to the FBG hydrophone outputs and the lower traces to the PZT hydrophone outputs. For the measurement at $20 \mathrm{kHz}$, the lower trace is from the standard PZT hydrophone (B\&K Type 8103). The output of the standard hydrophone is amplified by the condition amplifier type 2650 and connected to the oscilloscope. Since the standard hydrophone can be used only up to $200 \mathrm{kHz}$, other PZT hydrophones are used to monitor the acoustic field at 1 and $3 \mathrm{MHz}$. Small discrepancy in phase between the upper and lower traces in (a) does not mean the phase difference between their temporal responses but is due to the phase delay in the instruments. It is seen from the figures that the FBG hydrophone can detect a sound pressure with good temporal response from low frequencies to high frequencies. Since we have the similar waveforms in the upper and lower traces in (c), the shape showing relatively slow rising is considered not to be due to the characteristics of the hydrophones. It is considered to be probably because of the character of the acoustic transducer used in the experiment. While varying the sound pressure in water, the $\mathrm{CH} 1$ output of the oscilloscope and the output of the condition amplifier are measured by a lockin amplifier and a digital multimeter DMM, respectively. The acoustic frequency is $20 \mathrm{kHz}$. After calibrating the FBG hydrophone output with the standard hydrophone output, the output of the FBG hydrophone is plotted as a function of the sound pressure and shown in Fig. 5. The 


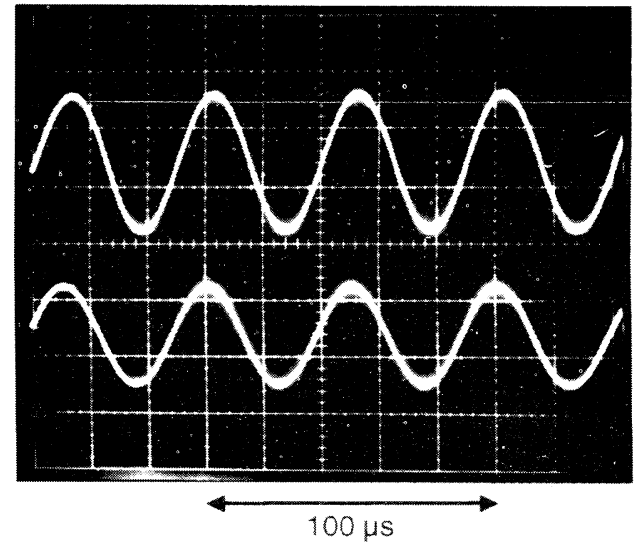

(a) $f_{A}=20[\mathrm{kHz}]$

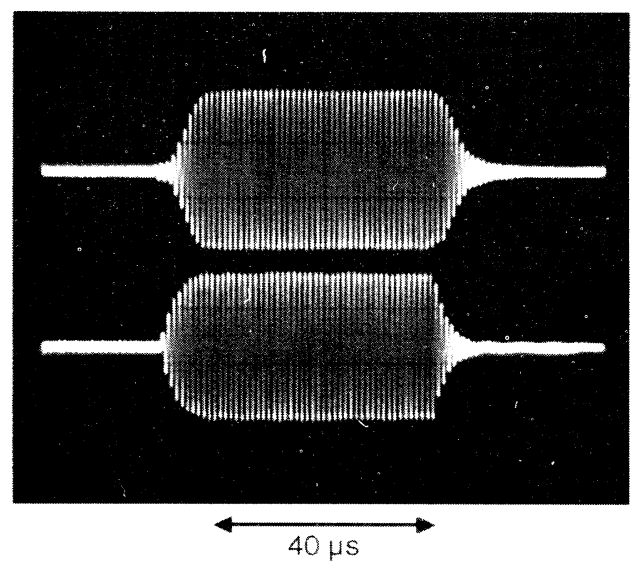

(b) $f_{A}=1[\mathrm{MHz}]$

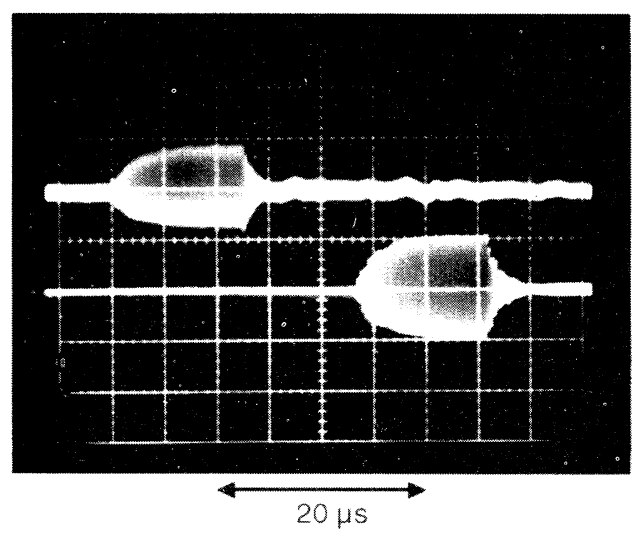

(c) $f_{A}=3[\mathrm{MHz}]$

Fig.4 Temporal response of FBG hydrophone for various frequencies. $f_{A}$ is the acoustic frequency. In each figure,the upper trace crresponds to the FBG hydrophone and the lower to the PZT hydrophone.

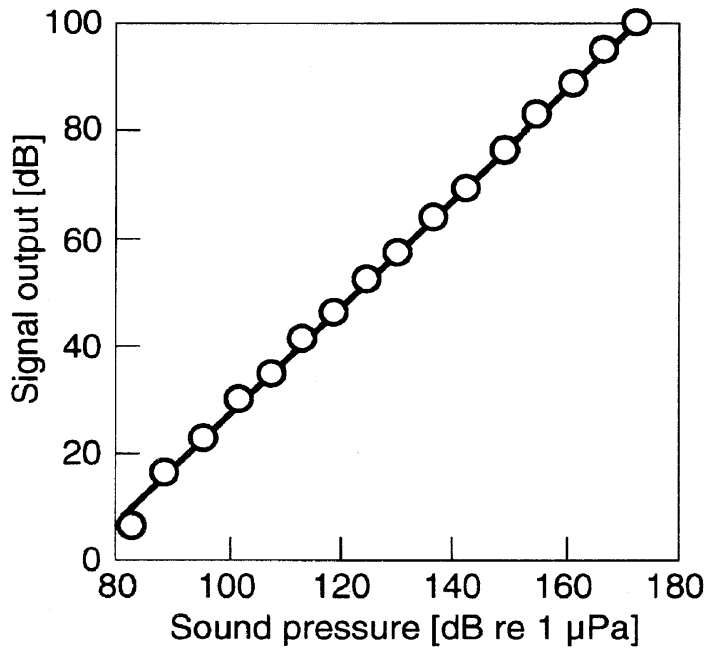

Fig.5 Sound pressure dependence of FBG hydrophone output.

vertical axis is in relative magnitude. The circles are the experimental results and the straight line is drawn with the curve fitting method. Since the slope of the line is 1.01 , it can be said that the FBG hydrophone output is in proportion to the sound pressure applied. The linearity is good and the dynamic range of the FBG hydrophone is as wide as about $90 \mathrm{~dB}$.

\subsection{Spatial distribution measurement of acoustic field}

As an application of the FBG hydrophone developed here, a spatial distribution of an acoustic field in water is measured using the experimental setup shown in Fig.6. The optical system in the setup is essentially the same as that in the previous section. The PZT acoustic transducer is placed in the water and an acoustic field is radiated in the horizontal direction. The FBG hydrophone can be moved in the $x$ (horizontal) and $z$ (vertical) directions with stepping motors, as shown in the figure. The stepping motors and the spectrum analyzer are connected to and controlled by a computer through RS232C and GPIB, respectively. The frequency of the acoustic field is $1 \mathrm{MHz}$ in pulsed mode. The operating optical wavelength is the same as above: 1544.67 $\mathrm{nm}$. The distance between the transducer and the FBG hydrophone head is $100 \mathrm{~mm}$. While 


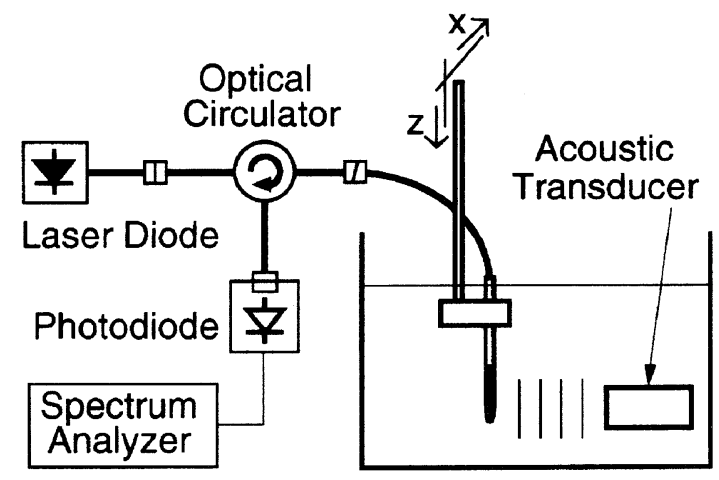

Fig.6 Spatial distribution measurement of acoustic field.

scanning the FBG hydrophone by $50 \times 50$ $\mathrm{mm}$ in the $x$ and $z$ directions, the output of the photodiode is measured and recorded in the computer. The result is shown in Fig.7(a). Fig.7(b) shows the same distribution obtained with the same procedures but with a PZT hydrophone instead of the FBG hydrophone. The size of the PZT hydrophone is $5 \mathrm{~mm}$ in diameter. In both cases, the outputs are normalized by their maximum values and given in relative magnitude. As seen in Fig. 7(a), the distribution of the acoustic field in water is measured with fairly good reso- lution by using the FBG hydrophone. Although there is some discrepancy between the results obtained by the two kinds of hydrophone, overall coincidence between them is fairly good.

\section{Summary}

A compact optical fiber hydrophone is developed and demonstrated using an FBG as a sensing element. An FBG hydrophone exhibits several important features. It can detect a sound pressure with good linearity and the dynamic range as wide as $90 \mathrm{~dB}$. It responds to an acoustic field from low to high frequencies: the operation from $20 \mathrm{kHz}$ to $3 \mathrm{MHz}$ has been experimentally examined. It provides a fairly good spatial resolution in detecting an acoustic field in water. The sensitivity of an FBG hydrophone can be raised by using higher input optical power and steeper slope of a reflection spectrum curve (see Eq. (3)). Although we used 3 $\mathrm{mW}$ of LD output power because of the limitation in our laboratory and $0.14 \mathrm{~nm}$ bandwidth due to the commercial availability, it is possible to obtain a higher power laser diode and a narrower bandwidth FBG. The sensitivity can then be easily made higher. Since an FBG can be made inherently at low cost, furthermore, it is ex-

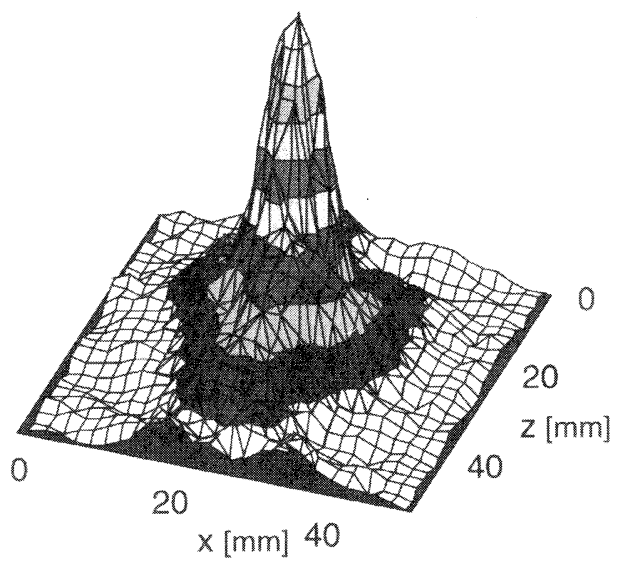

(a) FBG hydrophone

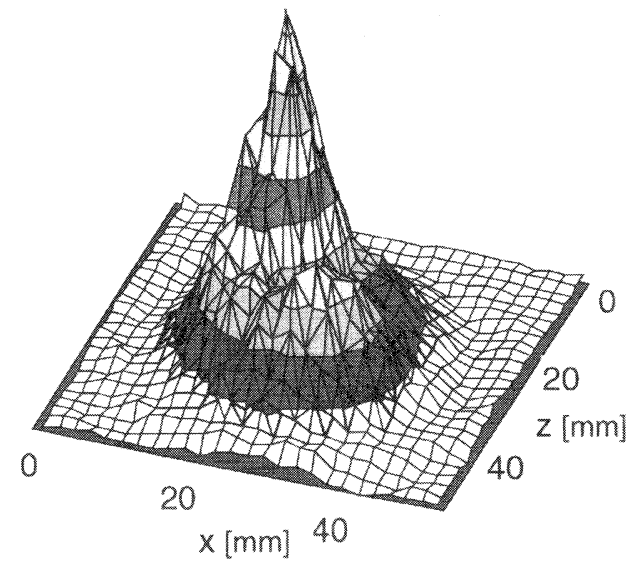

(b) PZT hydrophone

Fig.7 Spatial distribution of acoustic field in water. 
pected to offer a hydrophone of practical importance.

\section{References}

1) N. Takahashi, A. Hirose and S. Takahashi, "Underwater Acoustic Sensor with Fiber Bragg Grating," Opt. Rev., 4 (6), 691-694 (1997).

2) A. D. Kersey, M. A. Davis, H. J. Patrick, M. LeBlanc, K. P. Koo, C. G. Askins, M. A. Putnum and E. J. Friebele, "Fiber Grating Sensors," J. Lightwave Technol., 15 (8), 1442-1463 (1997).

3) J. P. Dakin and M. Volanthen, "Distributed and Multiplexed Fiber Grating Sensors," Proc. 13th International Conference on Optical Fiber Sensors, SPIE 3746, 134-140 (1999).

4) J. Jung, H. Nam, J. H. Lee, N. Park and B. Lee, "Simultaneous measurement of strain and temperature by use of a single-fiber Bragg grating and an erbium-doped fiber amplifier," Appl. Opt., 38 (13), 2749-2751 (1999).
5) L. A. Ferreira, J. L. Santos and F. Farahi, "Pseudoheterodyne Demodulation Technique for Fiber Bragg Grating Sensors Using Two Matched Gratings," IEEE Photon. Technol. Lett., 9 (4), 487-489 (1997).

6) S. Takahashi, T. Kikuchi, A. Hasegawa and Y. Murakami, "Cavitation noise measurement using a fiber-optic hydrophone," J. Acoust. Soc. Am., 87 (6), 2489-2492 (1990).

7) N. Takahashi, T. Saeki, K. Tetsumura and S. Takahashi, "Pressure and temperature dependence of fiber Bragg grating for acoustic sensing," J. Marine Acoust. Soc. Jpn., 26 (4), 98-105 (1999). 